\title{
Molecular Strategies to Treat Vascular Diseases Circulating Vascular Progenitor Cell as a Potential Target for Prophylactic Treatment of Atherosclerosis
}

\author{
Masataka Sata, MD
}

\begin{abstract}
Atherosclerosis is responsible for more than half of all deaths in Western countries. Numerous studies have reported that accumulation of smooth muscle cells (SMCs) plays a principal role in atherogenesis, post-angioplasty restenosis and transplantation-associated vasculopathy. Although much effort has been devoted to targeting the migration and proliferation of medial SMCs, effective therapy to prevent occlusive vascular remodeling has not been established. Recently, it was suggested that bone marrow-derived precursors can give rise to vascular cells that contribute to the repair, remodeling, and lesion formation of the arterial wall under certain circumstances. This review highlights the recent findings on circulating vascular precursors and describes the potential therapeutic strategies for vascular diseases, targeting mobilization, homing, differentiation and proliferation of circulating progenitor cells. (Circ J 2003; 67: 983-991)
\end{abstract}

Key Words: Atherosclerosis; Bone marrow; Gene therapy; Progenitor; Smooth muscle cell

$\mathbf{E}$ xuberant accumulation of smooth muscle cells (SMCs) plays a principal role in the pathogenesis of vascular diseases ${ }^{1-6}$ In atherosclerotic plaques, SMCs proliferate and synthesize extracellular matrix, thereby contributing to lesion formation. Percutaneous coronary interventions (PCIs) have been widely adopted for treatment of coronary atherosclerosis, but a significant number of these procedures fail because of post-angioplasty restenosis? Although the increasing use of new devices for dilatation of stenosed arteries has lowered the incidence of acute complications, restenosis still limits the long-term outcome of PCI8 SMC hyperplasia is also a major cause of post coronary bypass surgery occlusion ${ }^{9,10}$ and furthermore, graft vasculopathy, a leading cause of graft failure and retransplantation after the first postoperative year, ${ }^{11}$ results from SMC hyperplasia!1 ${ }^{1}$ Therefore, much effort has been devoted to understanding the molecular pathways that regulate SMCs hyperplasia in order to prevent vascular diseases ${ }^{1-4}$ However, the pathogenesis remains largely unknown and, consequently, effective therapy has not yet been established?

\section{Hypothesis of the Derivation of Neointimal Cells}

There is a widely accepted view that atherosclerotic lesions result from an excessive, inflammatory-fibroproliferative response to various forms of insult to the endothelium and smooth muscle of the artery wall1-4,12-14 In brief,

(Received September 22, 2003; revised manuscript received September 22, 2003; accepted September 24, 2003)

Department of Cardiovascular Medicine, University of Tokyo Graduate School of Medicine, Tokyo and PRESTO, Japan Science and Technology Agency, Kawaguchi, Saitama, Japan

Mailing address: Masataka Sata, MD, Department of Cardiovascular Medicine, University of Tokyo Graduate School of Medicine, 7-3-1 Hongo, Bunkyo-ku, Tokyo 113-8655, Japan. E-mail: sata-2im@h. u-tokyo.ac.jp after endothelial injury, inflammatory cells infiltrate and secrete various cytokines, such as tumor necrosis factora, interleukin- $\beta$, and interferon- $\gamma$, which trigger dedifferentiation of the medial SMCs that regulate vascular tone and blood flow under normal physiological conditions!,4 Dedifferentiated SMCs are characterized by a large cell body containing synthetic and secretary organelles, ${ }^{1,5,15-24}$ It has been hypothesized that dedifferentiated SMCs migrate into the subendothelial space, proliferate, and synthesize extracellular matrix ${ }^{2}$ and it has been assumed that all of the neointimal cells in post-angioplasty restenosis and graft vasculopathy are derived from medical SMCs? Thus, numerous pharmacological and gene therapies have been proposed to target the dedifferentiation, migration and proliferation of medial SMCs ${ }^{25-36}$ However, there are several phenomena that cannot be explained by the hypothesis.

First, very few studies have documented that SMCs migrate across the internal elastic lamina from the media into the subendothelial layer 1,4 On the other hand, many studies have shown that blood cells attach to the luminal side of the injured artery prior to the development of the neointimal hyperplasia that is composed exclusively of SMCs 37,38 Second, it has been observed that neointima can form after medial cells have been killed by severe injury (Fig 1) 37 That study noted that neointimal cells were negative for SMC markers and appeared to be hematopoietic rather than vascular cells at 1 week after injury. Third, many studies have reported that SMC hyperplasia can be prevented by blocking chemokines or adhesion molecules, 39,40 which play a crucial role in recruiting blood cells, but have no effect on the migration and proliferation of differentiated SMCs 39 Fourth, neointimal SMCs are quite distinct from medial SMCs in phenotypic and genetic expression patterns! $1,41,42$ Neointimal SMCs express a number of hematopoietic lineage markers, including FK506-binding protein 12 , interferon regulatory factor, and proinflammatory proteins, ${ }^{41,42}$ suggesting that some of the neointimal cells might be derived from blood cells rather than medial 
uninjured

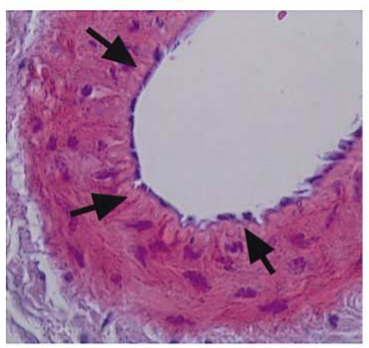

$1 \mathrm{~W}$

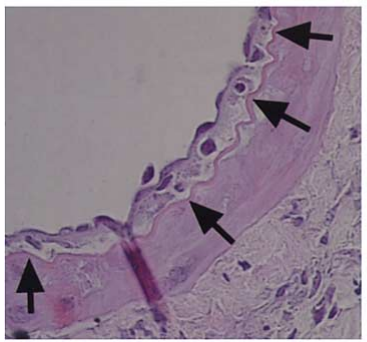

1D

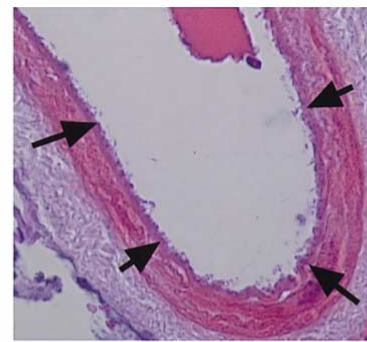

$2 W$

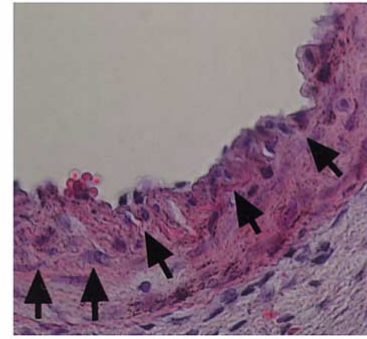

3D

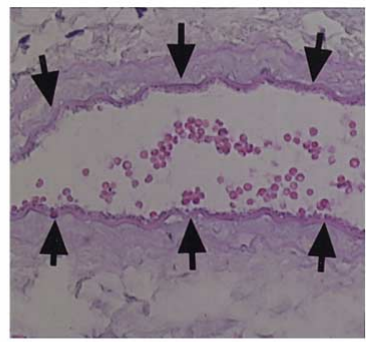

4W

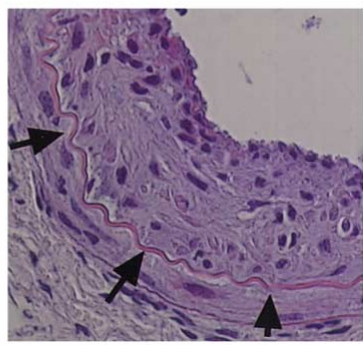

Fig 1. Neointima formation in the absence of medial cells. A large wire was inserted into the femoral artery of C57BL/6J mice. and the injured arteries were harvested at the time points indicated. The lumen of the injured artery remained dilated because of thinning of the media. At 1,3, and 7 days after the injury, the media contained only a few cells. At 1 week, thin neointimal formation was observed on the luminal side of the internal elastic lamina (arrows). The neointimal hyperplasia continued to grow for 3 or 4 weeks after which lesion formation ceased. Reproduced with permission from Elsevier Science (Reference 37).
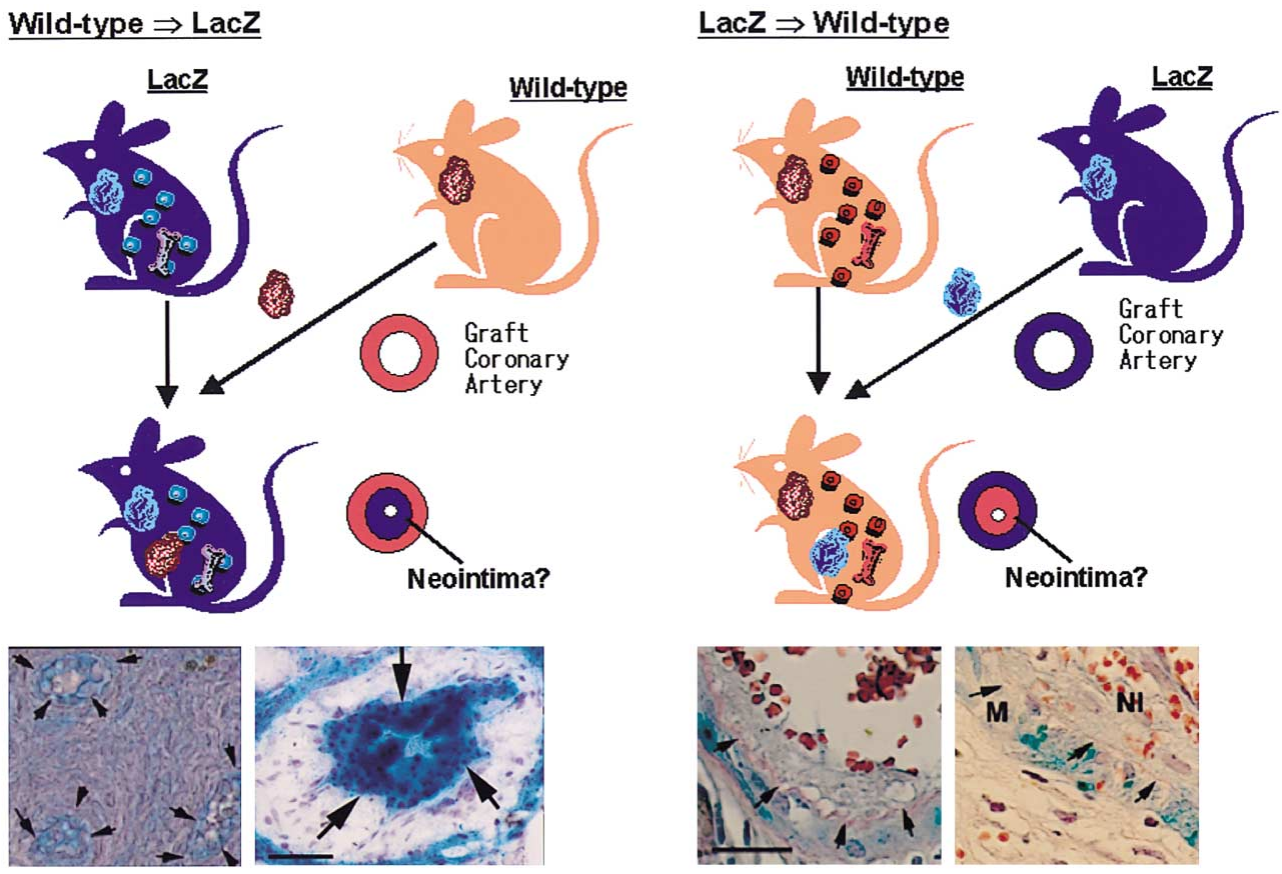

Fig 2. Contribution of recipient cells to graft-vasculopathy. When wild-type hearts were transplanted into LacZ mice, about $90 \%$ of the neointima cells were LacZ-positive and thus originating form the recipient (Left; Bar $=50 \mu \mathrm{m})$. Conversely, LacZ-negative recipient cells formed neointima on the LacZ-positive coronary arteries after cardiac transplantation from LacZ-mice to wild-type mice (Right; Bar $=25 \mu \mathrm{m}$ ). Arrows in histological panels indicate internal elastic lamina. Reproduced with permission from Nature Publishing Company (Reference 43).

SMCs. Evidence in support of this hypothesis has been provided in several models of vascular diseases ${ }^{43-46}$

\section{Bone Marrow Cells}

Contribution to Transplant-Associated Arteriosclerosis

The contribution of bone marrow cells (BMCs) was first 


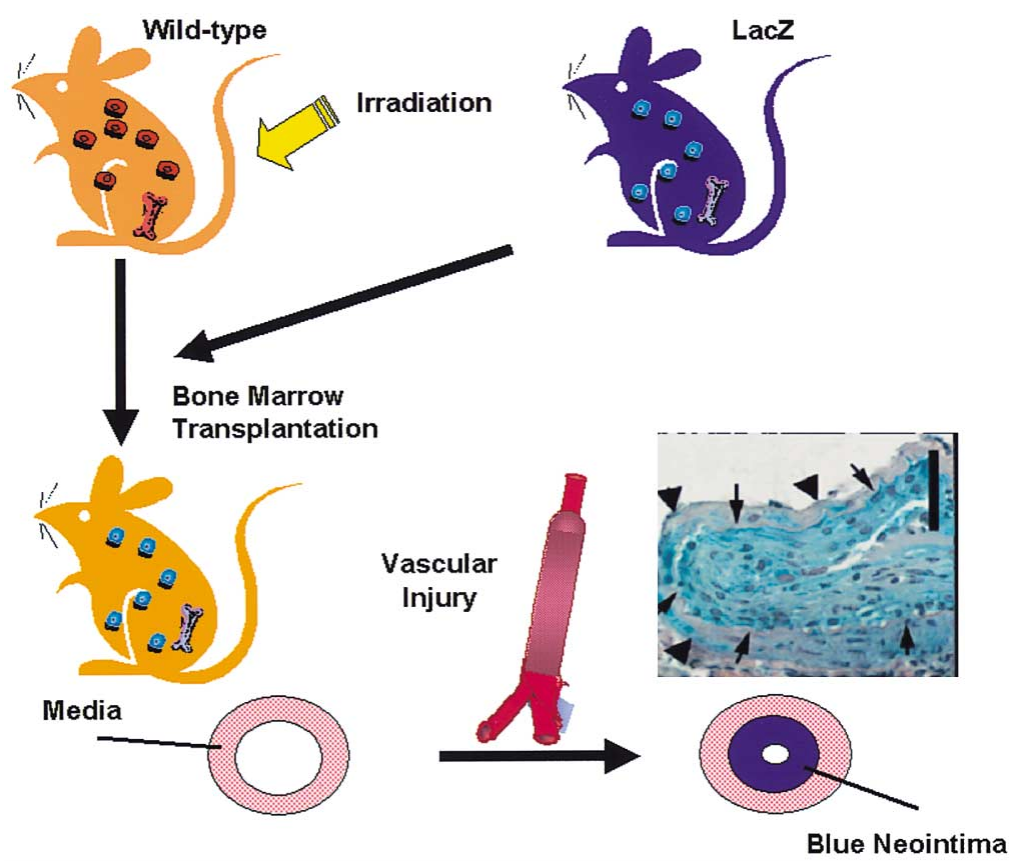

Fig 3. Contribution of bone marrow cells to healing and lesion formation after mechanical injury. A large wire was inserted into the femoral artery of wild-type mice whose bone marrow had been reconstituted with that of LacZ mice. Four weeks later there was neointima formation. Approximately $60 \%$ of the neointimal cells and $40 \%$ of the medial cells were LacZ-positive, and thus derived from the bone marrow. Arrows and arrowheads in histological panel indicate internal and external elastic lamina, respectively. Scale bar $=50 \mu \mathrm{m}$. Reproduced with permission from Nature Publishing Company (Reference 44). investigated in graft vasculopathy, a robust form of atherosclerosis that develops rapidly in transplanted organs, leading to failure of the allograft3,11 Heterotopic cardiac transplantation was carried out between wild-type mice and ROSA26 mice, ${ }^{43,44}$ which are knock-in mice expressing LacZ ubiquitously (LacZ-mice). ${ }^{47,48}$ Four weeks after transplantation, the allografts were harvested and stained with $\mathrm{X}$-gal (5-bromo-4-chloro-3-indolyl $\beta$-D-galactopyranoside) (Fig 2). The lumens of the large epicardial coronary arteries, their smaller branches and arterioles were found to have narrowed because of concentric neointimal hyperplasia, the majority of which was composed of recipient cells expressing LacZ.43,44 It was also observed that some of the medial SMCs, as well as endothelial cells (ECs), had been replaced by recipient cells. Immunofluorescence studies revealed that the LacZ-positive cells in the neointima expressed various markers for SMCs, including myosin heavy chain, calponin, $h$-caldesmon, and $\mathbf{\alpha}$-smooth muscle actin ( $\mathbf{a}$ SMA) ${ }^{4}$ Conversely, when LacZ-positive hearts were transplanted into wild-type mice, LacZ-negative neointima developed on the LacZ-positive coronary arteries. Furthermore, in situ hybridization of the allografts from female to male mice revealed that most of the neointimal cells corresponded to cells from the recipients. ${ }^{43}$ These results indicated that the majority of the neointimal cells were derived from the recipient cells, but not from the medial cells of donor origin. Consistent with these observations, others independently reported that recipient cells are a major source of graft vasculopathy in the aortic transplantation model ${ }^{49-54}$ Moreover, it has been reported that in human transplant-associated arteriosclerosis after renal transplantation most of the neointimal cells and ECs are derived from the recipient 55,56

To identify the potential source of recipient cells that contribute to allograft vasculopathy, bone marrow transplantation (BMT) was performed from LacZ mice to wildtype mice (BMTLacZ $\rightarrow$ wild mice). After 4-8 weeks, wildtype hearts were transplanted into the BMTLacZ $\rightarrow$ wild mice, and 4 weeks later most of the neointimal cells were found to be LacZ-positive. Similarly, when wild-type hearts were transplanted into wild-type mice whose bone marrow had been reconstituted with that of transgenic mice that ubiquitously expressed enhanced green fluorescent protein (GFP mice) (BMTGFP $\rightarrow$ wild mice $)^{44}$ it was observed that GFPpositive cells accumulated on the luminal side of the graft coronary arteries. The immunofluorescence study revealed that some of the GFP-positive cells in graft vasculopathy expressed $\alpha$-SMA. These results indicate that recipient BMCs may substantially contribute to neointimal formation in transplanted grafts.

\section{Contribution to Vascular Remodeling After Mechanical Injury}

BMCs can also contribute to the pathogenesis of lesion formation after mechanical vascular injury (Fig 3).4-46 The bone marrow of wild-type mice were replaced with that of LacZ-mice (BMTLacZ $\rightarrow$ wild mice) and it was found that transplanted LacZ BMCs had settled in bone marrow, spleen, and thymus, whereas LacZ-positive cells were not detected in the uninjured femoral arteries of the BMTLacZ $\rightarrow$ wild mice. Four to 8 weeks after BMT, a large wire was inserted into the femoral artery of the BMTLacZ $\rightarrow$ wild mice, being a new method of vascular injury that resembles balloon angioplasty ${ }^{37}$ This injury led to complete denuding of the endothelium and marked enlargement of the lumen (Fig 1)37,57,58 The cellularity of the medial layer decreased because of acute onset of SMC apoptosis 37,57,58 One week after the injury, the artery remained dilated and X-gal staining revealed that LacZ-positive cells were attached to the luminal side of the injured vessels. The LacZ-positive cells did not express the marker for SMCs (ie, a-SMA) or that for ECs (ie, CD31). The dilated lumen gradually narrowed because of neointimal hyperplasia, which was primarily composed of SMCs. A significant number of the neointimal and medial cells were LacZ-positive on X-gal staining44,46 Immunofluorescence double-staining documented that some bone marrow-derived LacZ positive cells in the neointimal lesions expressed a-SMA or CD3146 These results indicate that $\mathrm{BMCs}$ may give rise to vascular cells, thereby contributing to the arterial remodeling after the 

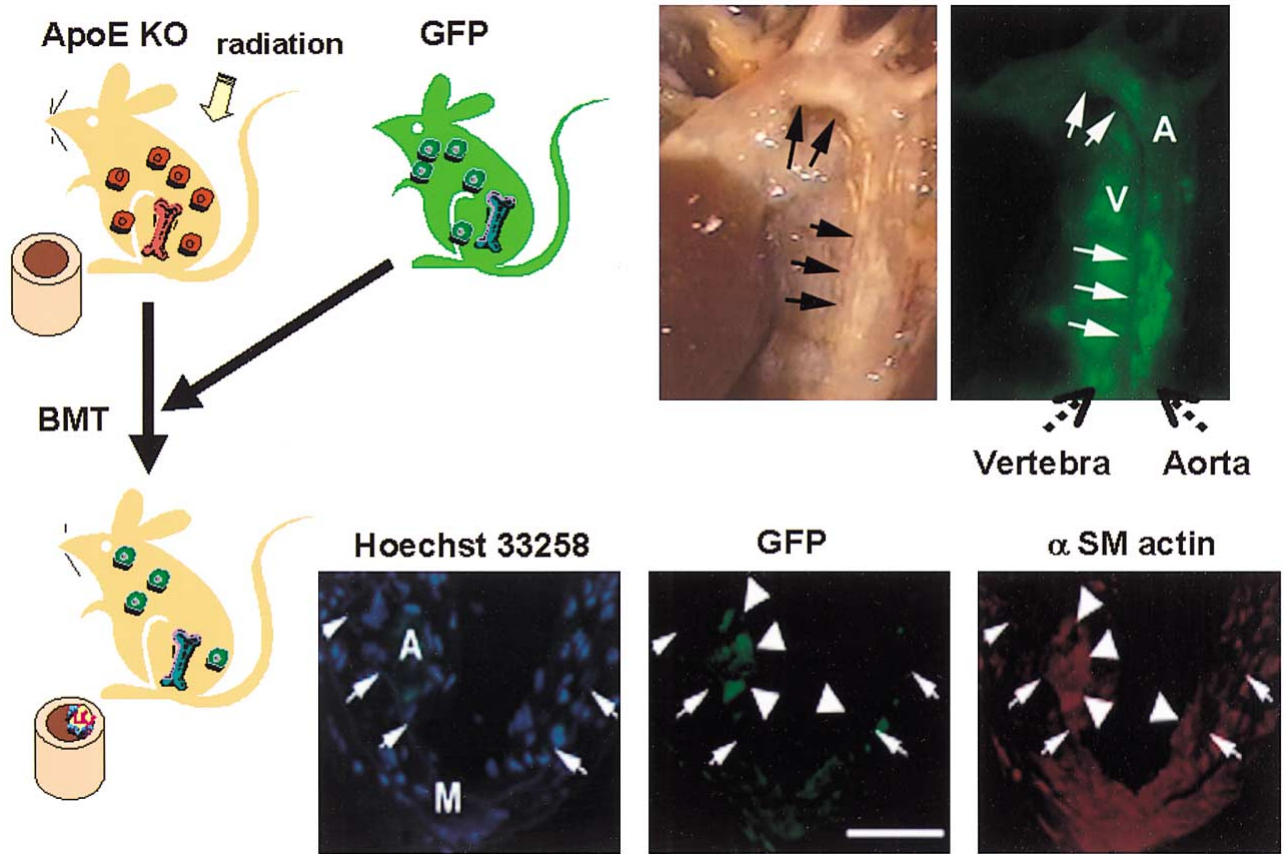

Fig 4. Bone marrow-derived smooth muscle cells (SMCs) in atherosclerotic plaques. Bone marrow transplantation was performed from GFP-mice to ApoE-deficient mice. After being fed a Western-type diet, the aortas of BMTGFP $\rightarrow$ ApoE- $/-$ mice were observed under a xenon fiber optic light source. Arrows indicate atherosclerotic plaques. A, aorta; V, vertebra. Cross-sections of the aortas of the BMTGFP $\rightarrow$ ApoE- - - mice were stained with Cy3-conjugated antia smooth muscle actin antibody (red) and Hoechst 33258 (blue). Arrows indicate internal elastic lamina. Arrowheads indicate GFP-positive cells (green) expressinga -smooth muscle actin ( $\mathrm{a}$ SM actin, red) in atherosclerotic lesions. Scale bar $=50 \mu \mathrm{m}$. Reproduced with permission from Nature Publishing Company (Reference 44).

wire-mediated endovascular injury.

\section{Bone Marrow-Derived SMC-Like Cells in Atherosclerotic Plaques}

To investigate the potential source of the SMCs observed in atherosclerotic plaques, 4 the bone marrow of 8-weekold ApoE -/- mice was replaced with that of GFP-mice $\left(\mathrm{BMT}{ }_{\mathrm{GFP} \rightarrow \mathrm{ApoE}-1-}\right.$ mice) or ROSA26-mice (BMT $\mathrm{LacZ} \rightarrow \mathrm{ApoE}-1-$ mice) $)^{44}$ The recipient mice were fed a Western-type diet for 8 weeks, starting at 4 weeks after BMT 99 GFP-positive cells accumulated in atherosclerotic plaques developing in the aortas of the BMTGFP $\rightarrow$ ApoE-l- mice (Fig 4). Immunofluorescence study of cross sections of the vessels revealed that some of the GFP-positive cells expressed markers for SMCs (ie, a-SMA). Similarly, in the atherosclerotic lesions of the BMT ${ }^{\mathrm{LaCZ} \rightarrow \mathrm{ApoE}-/-}$ mice, some of the LacZ-positive cells expresseda-SMA. Furthermore, immunogold-labeling for LacZ identified bone marrow-derived SMC-like cells with muscle fibers in the atherosclerotic plaques of BMTLacZ $\rightarrow$ ApoE- $/-$ mice. The SMC-like cells displayed a typical 'synthetic' phenotype. These results suggest that some of the SMC-like cells observed in hyperlipidemiainduced atherosclerotic plaques may originate from bone marrow.

\section{New Mechanism for SMC Accumulation in Vascular Lesions}

Coronary angioplasty causes vessel wall injury and induces SMC proliferation with subsequent abundant production of extracellular matrix. Transplant-associated arteriosclerosis is also considered a consequence of an immunological attack against the allograft by the recipient 3,11
Various atherogenic substances, such as oxidized low density lipoprotein ${ }^{60-62}$ homocysteine ${ }^{63}$ angiotensin II ${ }^{64}$ and lipopolysaccharides, ${ }^{65}$ have been reported to induce vascular cell apoptosis, presumably initiating the earliest phase of lesion development in atherosclerosis ${ }^{66}$ Therefore, neointima formation appears to be similar to the healing process in response to vascular injuries. In addition to the conventional assumption that damaged tissues are repaired by individual parenchymal cells, an accumulating body of evidence indicates that there exist somatic stem cells that are mobilized to remote organs, differentiate into required lineages and participate in organ repair and regeneration ${ }^{67-72}$ It has been also reported that Flk-1 positive cells derived from mouse embryonic stem (ES) cells can act as vascular progenitor cells that contribute to fetal and adult neovascularization?3,74 Bone marrow might be an additional source of vascular cells that contribute to both vascular repair and the pathological remodeling at least in models of post-angioplasty restenosis, transplant-associated arteriosclerosis and hyperlipidemia-induced atherosclerosis.

\section{Diverse Origins of Neointimal Cells}

Of course, bone marrow could not be the only source of neointimal cells.5 Numerous reports have shown that neointimal cells are heterogeneous and that the SMCs in vascular lesions are composed of cells of diverse origins! $16,46,75$ Recently, we also reported that the cellular constituents differ according to the type of vascular injury ${ }^{46}$ Three distinct types of mechanical injuries were induced in the same mouse whose bone marrow had been reconstituted with that of GFP- or LacZ- mice (Fig 5). After wire-mediated endovascular injury, a significant number of the neointimal and 


\section{Flow-restriction by ligation}

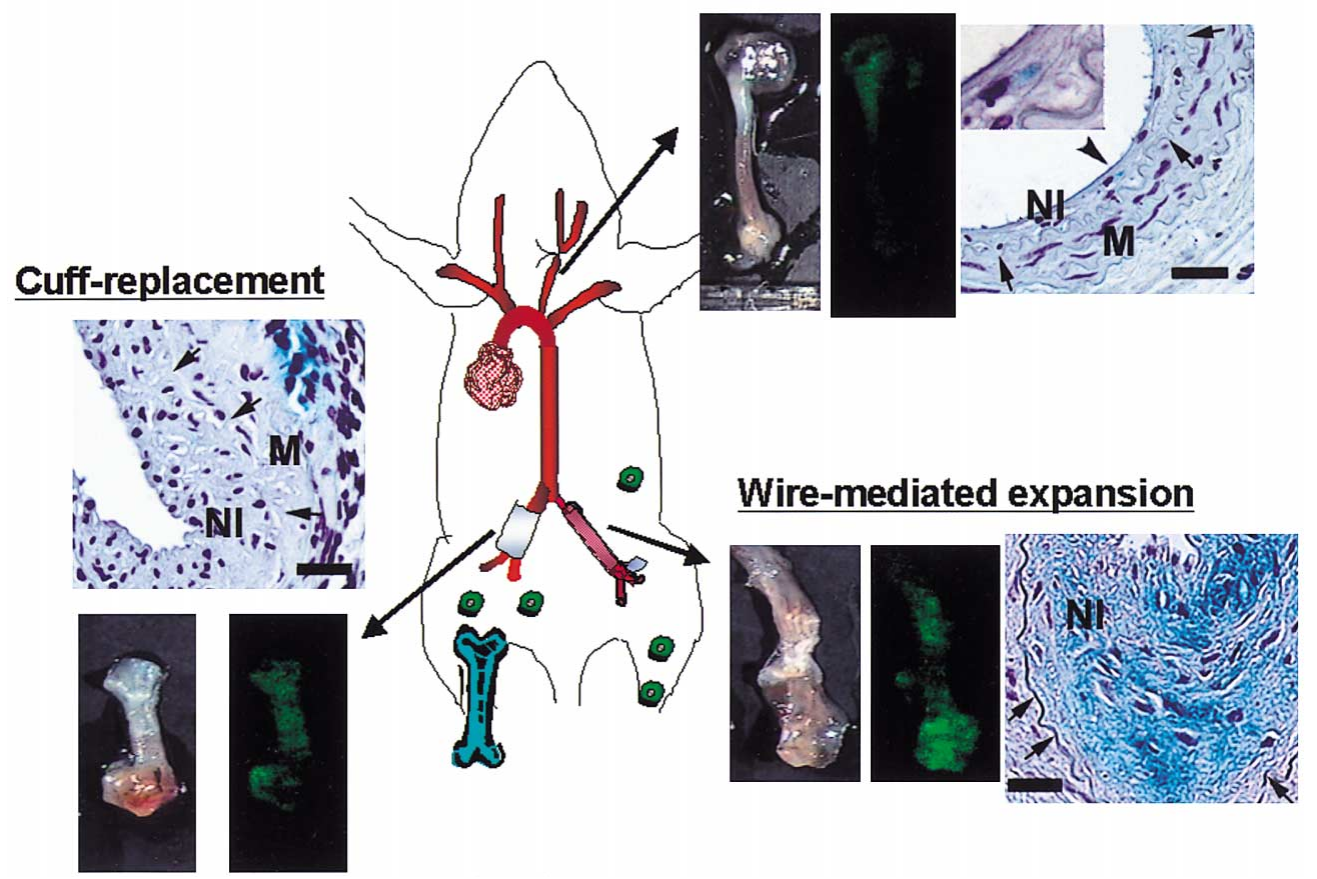

Fig 5. Marked diversity in the contribution of bone marrow-derived cells to vascular remodeling. Three distinct types of mechanical injuries were induced in the same mouse whose bone marrow had been reconstituted with that of GFP- or LacZ- mice. Endovascular injury was induced by inserting a large wire into the left femoral artery (Wire-mediated expansion), a perivascular injury was induced by placing a polyethylene tube around the right femoral artery of the same mouse (Cuff-replacement) and a flow-restriction vascular injury was induced by ligating the left common carotid artery (Flowrestriction by ligation). The injured arteries of $\mathrm{BMTGFP} \rightarrow \mathrm{ApoE}-{ }_{-}$mice were harvested after 4 weeks and observed with a GFP-lighting system and a cooled CCD camera (Macroscopic panels). Scale bar $=1 \mathrm{~mm}$. The injured arteries from the BMTLacZ $\rightarrow$ Wild mice were stained with X-gal to detect LacZ. Paraffin-embedded sections were rehydrated and stained with hematoxylin. Arrows indicate the internal elastic lamina. Arrowheads indicate LacZ+ cells (Histological panels). Scale bar $=20 \mu \mathrm{m}$. Reproduced with permission from Lippincott Williams \& Wilkins (Reference 46).

medial cells were found to be derived from bone marrow. In contrast, marker-positive cells were seldom detected in the lesion induced by perivascular cuff replacement. There were only a few bone marrow-derived cells in the neointima following ligation of the common carotid artery. These findings suggest that the mode of injury is crucial for the recruitment of bone marrow-derived cells to tissue remodeling.

Given the complexity of human atherosclerotic lesions, none of the vascular injury models would represent the exact pathogenesis. It has been suggested that BMCs would substantially contribute to lesion formation when arteries are subjected to severe injuries.6 Advanced atherosclerotic lesions exhibit a higher incidence of internal elastic rupture and intimomedial interface damage ${ }^{76}$ both of which are associated with focal intraplaque microhemorrhage?7 Angioplasty completely denudes the endothelium and mechanically dilates atherosclerotic lesions with a tear in the luminal surface ${ }^{78}$ It is likely that circulating progenitors substantially contribute to vascular remodeling in humans when arteries are subjected to severe injuries, such as PCI, transplantation and plaque rupture.4-46,57,58,79 Consistent with this notion, an analysis of sex-mismatched bone marrow transplant subjects revealed that SMCs throughout the atherosclerotic vessel wall are derived from the donor bone marrow ${ }^{80}$ Of interest is a finding that recruitment of bone marrow-derived SMCs was more extensive in diseased compared with undiseased segments.

\section{Bone Marrow Cell Types Contributing to Vascular Remodeling}

Pluripotent cells have been identified in bone marrow and are classified into hematopoietic stem cells (HSCs) ${ }^{81}$ and mesenchymal stem cells?2 Although it has been assumed that HSCs give rise only to blood cells of hematopoietic lineage, recent reports suggest that they may have the broader potential to differentiate into various cell types, including epithelial cells ${ }^{83}$ hepatocytes ${ }^{84,85}$ and cardiomyocytes ${ }^{68,86}$ To identify the BMCs that have the potential to generate vascular cells, a HSC-enriched fraction (c-Kit ${ }^{+}$, Sca-1+, $\mathrm{Lin}^{-}$) was isolated from the bone marrow of LacZmice by fluorescence-activated cell sorting. ${ }^{44}$ Next, 3,000 cells were injected into lethally irradiated wild-type mice. Four weeks after bone marrow reconstitution, the femoral artery of the recipient mice was mechanically injured with a large wire ${ }^{37}$ and 4 weeks later, the injured arteries showed neointimal hyperplasia. The neointima and the media contained many LacZ-positive cells.4 ${ }^{44}$ Some LacZ-positive cells expressed a-SMA. LacZ-positive cells also contributed to endothelial regeneration44 These findings suggest that the $\mathrm{c}-\mathrm{Kit}^{+}, \mathrm{Sca}-1^{+}, \mathrm{Lin}^{-}$fraction of BMCs may have the potential to differentiate into either the SMCs or ECs that participate in vascular remodeling.

Recently, Wagers et al extensively analyzed uninjured organs of wild-type mice whose bone marrow had been reconstituted with a single HSC and concluded that trans- 


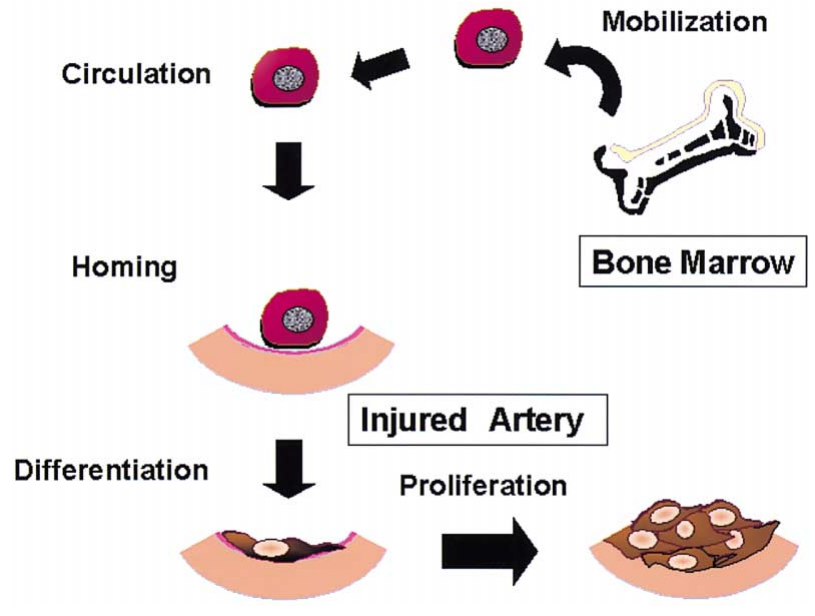

Fig 6. Therapeutic strategies targeting putative vascular progenitor cells. Research findings provide the basis for the development of new therapeutic strategies for vascular diseases, targeting the mobilization, circulation, homing, differentiation and proliferation of bone marrowderived vascular progenitor cells.

differentiation of HSCs into other lineages is an extremely rare event ${ }^{87}$ In the aforementioned study, 44 the recipient bone marrow was reconstituted with 3,000 cells of the c$\mathrm{Kit}^{+}, \mathrm{Sca}-1^{+}, \mathrm{Lin}^{-}$fraction, which substantially contributed to arterial remodeling after wire-mediated injury. The apparent discrepancy in the results of these 2 studies could merely derive from the analysis of non-injured versus injured tissues. Moreover, although the $\mathrm{c}-\mathrm{Kit}^{+}, \mathrm{Sca}-{ }^{+}, \mathrm{Lin}^{-}$ fraction is supposed to be enriched in $\mathrm{HSCs}^{85}$ non-hematopoietic cells may potentially contaminate the population. It remains unclear whether a highly purified single HSC can give rise to neointimal cells as the $\mathrm{c}-\mathrm{Kit}^{+}, \mathrm{Sca}^{-1}{ }^{+}, \mathrm{Lin}^{-}$ fraction does. It is possible that the contaminated non-hematopoietic (CD45-negative) cells rather than the hematopoietic (CD45-positive) cells contributed to neointimal formation after vascular injury. My group is currently determining whether a HSC can transdifferentiate into vascular cells by analyzing the vascular lesions produced in the mice whose bone marrow has been reconstituted by a single HSC.

\section{Cell Fusion as a Possible Mechanism of BMC 'Differentiation'}

Recent evidence suggests that there somatic stem cells or adult stem cells remain in the adult ${ }^{8}$ Many animal experiments have documented that adult stem cells can transdifferentiate into other lineages? ${ }^{2,83,89,90}$ In gender-mismatched human BMT, it has been reported that donor-derived hematopoietic stem cells participated in organ regeneration 83,85 On the other hand, the results of recent studies suggest that adult stem cells adopt a tissue-specific phenotype by cell fusion, in vitro 91,92 and in vivo, 93,94 but not by transdifferentiation. Consistent with this notion, polyploidization of vascular SMCs in response to mechanical and humoral stimuli has been documented ${ }^{95}$ Thus, it is possible that cell fusion can account for, at least in part, the accumulation of bone marrow-derived SMC-like cells in vascular lesions, ${ }^{45}$ although spontaneous cell fusion between recipient and donor-derived cells seems to be a rare event in a murine model of cardiac transplantation? 96

\section{Therapeutic Strategies Targeting Circulating Vascular Progenitor Cells}

Although a lot of effort has been devoted to targeting the migration and proliferation of medial SMCs, effective therapy to prevent vascular lesions has not yet been established. Our findings indicate that bone marrow-derived smooth muscle progenitor cells might become additional targets (Fig 6). ${ }^{45}$ Consistent with this notion is a previous observation that transient myelosuppression inhibited SMC hyperplasia in balloon-injured coronary arteries97 Similar effects could be obtained by inhibition of a chemokine ${ }^{39}$ or an adhesion molecule, ${ }^{40}$ which may play a crucial role in the recruitment and homing of putative SMC progenitors. Recently, a sirolimus-eluting stent has emerged as a promising strategy to inhibit post-PCI restenosis98,99 In spite of increasing clinical enthusiasm, very little is known as yet about the mechanism by which the stent effectively prevents neointimal hyperplasia. Sirolimus is an immunosuppressive drug, which is supposed to have relatively little effect on medial SMCs. ${ }^{41}$ It is possible that sirolimus effectively inhibits accumulation of bone marrow-derived vascular precursors when delivered locally at the site of progenitor cell accumulation.

\section{Possible Gene Therapy}

Several gene therapies targeting putative vascular progenitors are being studied, particularly the potential utilities of the Fas/Fas ligand system.100,101 Fas is a death receptor that transmits an apoptosis-inducing signal when activated by its ligand, Fas ligand (FasL) ${ }^{102,103}$ Recent observations of the Fas system in the vasculature indicate that ectopic or augmented expression of FasL may be useful for treating vascular diseases. ${ }^{104-106}$ FasL induces apoptosis in Fasbearing vascular SMCs, ${ }^{104}$ whereas ECs are refractive to FasL overexpression.104,107,108 Thus, the local delivery of FasL to sites of balloon injury is predicted to reduce the number of SMCs by inducing apoptotic cell death, while not inhibiting the beneficial process of re-endothelialization at the same site ${ }^{104,109}$ Moreover, local delivery of FasL should also kill bone marrow-derived progenitors as well as inflammatory cells at these lesions because these cells express Fas! 06,107 Consistent with this notion, it was reported that ECs can be genetically modified by adenovirusmediated gene transfer to overexpress functional, cellsurface FasL without undergoing self-destruction. ${ }^{109}$ In a rodent model of transplant graft vasculopathy, endothelial overexpression of FasL attenuated homing of hematopoietic cells at 1 week post-transplantation ${ }^{105}$ and the vessels also displayed reduced neointima formation at 1 and 2 months post-transplantation. These results indicate that endothelial cell-specific overexpression of FasL may have utility in the treatment of transplant arteriosclerosis by preventing accumulation of smooth muscle progenitors. Similar therapeutic strategies may be effective for prophylactic treatment of other types of vascular diseases.

\section{Implications for Regenerative Medicine}

There is an accumulating body of evidence that in adult there are somatic stem cells that can differentiate into various lineages $67,85,88,110$ This has aroused enthusiasm for the potential use of somatic stem cells for 'cell transplantation therapy' and 'tissue engineering' 67 However, given the pluripotency of adult stem cells, they may potentially differentiate into unfavorable cell types. In fact, there are a 
number of similarities between stem cells and cancer cells, ${ }^{11}$ and there is evidence that somatic stem cells do participate in pathological remodeling in remote organs. 43,44 For clinical use of adult stem cells, attention must be paid to potential adverse effects as well as beneficial aspects caused by the transplanted stem cells.

\section{Future Directions}

Further studies are needed to identify and characterize putative vascular progenitor cells. It has been observed that bone marrow-derived cells were negative for the markers of SMCs and ECs when they homed on the luminal side of the artery at 1 week after the mechanical injury, ${ }^{44}$ so it is likely that plastic, immature cells may be mobilized to the injured vessels, where they differentiate in response to mechanical and humoral stimuli. Consistent with that, it has been reported that blood cells contain progenitors that have the potential to differentiate into either ECs or SMCs in vitro according to the composition of the culture medium? ${ }^{79,80,112,113}$ Experiments that dissect the molecular mechanisms by which progenitors are recruited and differentiate at the site of injury are required.

\section{Conclusions}

In summary, the findings of research to date indicate that BMCs, including hematopoietic stem cells, contribute not only to the healing process of injured organs, but also to pathological remodeling. These findings provide the basis for the development of new therapeutic strategies for vascular diseases, targeting the mobilization, homing, differentiation and proliferation of bone marrow-derived vascular progenitor cells.

\section{Acknowledgments}

This study was supported in part by grants from Ministry of Education, Culture, Sports, Science and Technology (15039213, 15390241, and 15659180) and Ministry of Health, Labor and Welfare.

I thank Yoshie Maejima, Hiromi Kato-Nakajima, Fumiko Adachi, Takaaki Hasegawa, Yumi Sugawara, Mariko Kinoshita, Nobuko Nangi, Miwa Washida, Yukari Kaneda and Satoru Fukuda for their excellent technical assistance.

\section{References}

1. Ross R. Atherosclerosis: An inflammatoy disease. $N$ Engl J Med 1999; 340: $115-126$.

2. Ross R. Atherosclerosis: A defense mechanism gone awry (RousWhipple Award Lecture). Am J Pathol 1993; 143: 987-1002.

3. Ross R. Genetically modified mice as models of transplant atherosclerosis. Nat Med 1996; 2: 527-528.

4. Ross R. The pathogenesis of atherosclerosis: A perspective for the 1990s. Nature 1993; 362: 801-809.

5. Walsh K, Perlman H. Molecular strategies to inhibit restenosis: Modulation of the vascular myocyte phenotype. Semin Interv Cardiol 1996; 1: 173-179.

6. Walsh K, Smith RC, Kim HS. Vascular cell apoptosis in remodeling, restenosis, and plaque rupture. Circ Res 2000; 87: 184-188.

7. Nobuyoshi M, Kimura T, Nosaka H, Mioka S, Ueno K, Yokoi H, et al. Restenosis after successful percutaneous transluminal coronary angioplasty: Serial angiographic follow-up of 229 patients. J Am Coll Cardiol 1988; 12: 616-623.

8. Kearney M, Pieczek A, Haley L, Losordo DW, Andres V, Schainfeld R, et al. Histopathology of in-stent restenosis in patients with peripheral artery disease. Circulation 1997; 95: 1998-2002.

9. Callow AD. Molecular biology of graft occlusion. Curr Opin Cardiol 1995; 10: 569-576.

10. Sarjeant JM, Rabinovitch M. Understanding and treating vein graft atherosclerosis. Cardiovasc Pathol 2002; 11: 263-271.

11. Billingham ME. Cardiac transplant atherosclerosis. Transplant Proc 1987; 19: 19-25.
12. Ross R, Glomset JA. The pathogenesis of atherosclerosis. $N$ Engl J Med 1976; 295: 369-377.

13. Ross R, Glomset JA. Atherosclerosis and the arterial smooth muscle. Science. 1973; 180: 1332-1339.

14. Ross R. Cell biology of atherosclerosis. Annu Rev Physiol 1995; 57: $791-804$

15. Barrett TB, Sampson P, Owens GK, Schwartz SM, Benditt EP. Polyploid nuclei in human artery wall smooth muscle cells. Proc Natl Acad Sci USA. 1983; 80: 882-885.

16. Li S, Fan YS, Chow LH, Van Den Diepstraten C, van Der Veer E, Sims SM, et al. Innate diversity of adult human arterial smooth muscle cells: Cloning of distinct subtypes from the internal thoracic artery. Circ Res 2001; 89: 517-525.

17. Sjölund M, Rahm M, Claesson-Welsh L, Sejersen T, Heldin C-H, Thyberg J. Expression of PDGFa - and $\beta$-receptors in rat arterial smooth muscle cells is phenotype and growth state dependent. Growth Factors 1990; 3: $191-203$.

18. Basson CT, Kocher O, Basson MD, Asis A, Madri JA. Differential modulation of vascular cell integrin and extracellular matrix expression in vitro by TGF-beta 1 correlates with reciprocal effects on cell migration. J Cell Physiol 1992; 153: 118-128.

19. Campbell GR, Campbell JH. The phenotypes of smooth muscle expressed in human atheroma. Ann NY Acad Sci 1990; 598: 143-158.

20. Chamley-Campbell JH, Campbell GR. What controls smooth muscle phenotype? Atherosclerosis 1981; 40: 347-357.

21. Johnson RJ, Iida H, Alpers CE, Majesky MW, Schwartz SM, Pritzi $\mathrm{P}$, et al. Expression of smooth muscle cell phenotype by rat mesangial cells in immune complex nephritis: Alpha-smooth muscle actin is a marker of mesangial cell proliferation. J Clin Invest 1991; 87: $847-858$.

22. Majesky MW, Giachelli CM, Reidy MA, Schwartz SM. Rat carotid neointimal smooth muscle cells reexpress a developmentally regulated mRNA phenotype during repair of arterial injury. Circ Res 1992; 71: 759-768.

23. Manderson JA, Mosee PRL, Safstron JA, Young SB, Campbell GR. Balloon catheter injury to rabbit carotid artery. I: Changes in smooth muscle phenotype. Arteriosclerosis 1989; 9: 289-298.

24. Simonson MS, Walsh K, Kumar CC, Bushel P, Herman WH. Two proximal CArG elements regulate SMa-actin promoter, a genetic marker of activated phenotype of mesangial cells. Am J Physiol 1995; 268: F760-F769.

25. Clausell N, Milossi S, Sett S, Rabinovitch M. In vivo blockade of tumor necrosis factora in cholesterol-fed rabbits after cardiac transplant inhibits acute coronary artery neointimal formation. Circulation 1994; 89: 2768-2779.

26. Chang MW, Barr E, Lu MM, Barton K, Leiden JM. Adenovirusmediated over-expression of the cyclin/cyclin-dependent kinase inhibitor, p21 inhibits vascular smooth muscle cell proliferation and neointima formation in the rat carotid artery model of balloon angioplasty. J Clin Invest 1995; 96: 2260-2268.

27. Smith RC, Wills KN, Antelman D, Perlman H, Truong LN, Krasinski K, et al. Adenoviral constructs encoding phosphorylation-competent full-length and truncated forms of the human retinoblastoma protein inhibit myocyte proliferation and neointima formation. Circulation 1997; 96: 1899-1905.

28. Pollman MJ, Hall JL, Mann MJ, Zhang L, Gibbons GH. Inhibition of neointimal cell bcl-x expression induces apoptosis and regression of vascular disease. Nature Med 1998; 4: 222-227.

29. Chen D, Krasinski K, Chen D, Sylvester A, Chen J, Nisen PD, et al. Down-regulation of cyclin-dependent kinase activity and cyclin A promoter activity in vascular smooth muscle cells by p27 (KIP-1), an inhibitor of neointima formation in the rat carotid artery. $J$ Clin Invest 1997; 99: 2334-2341.

30. George SJ, Johnson JL, Angelini GD, Newby AC, Baker AH. Adenovirus-mediated gene transfer of the human TIMP-1 gene inhibits smooth muscle cell migration and neointimal formation in human saphenous veins. Hum Gene Ther 1998; 9: 867-877.

31. George SJ, Angelini GD, Capogrossi MC, Baker AH. Wild-type p53 gene transfer inhibits neointima formation in human saphenous vein by modulation of smooth muscle cell migration and induction of apoptosis. Gene Ther 2001; 8: 668-676.

32. Izawa A, Suzuki J, Takahashi W, Amano J, Isobe M. Tranilast inhibits cardiac allograft vasculopathy in association with p21 (Waf1/Cip1) expression on neointimal cells in murine cardiac transplantation model. Arterioscler Thromb Vasc Biol 2001; 21: $1172-1178$.

33. Rebsamen MC, Sun J, Norman AW, Liao JK. 1-alpha, 25dihydroxyvitamin D3 induces vascular smooth muscle cell migration via activation of phosphatidylinositol 3-kinase. Circ Res 2002; 91: $17-24$. 
34. Ohno T, Gordon D, San H, Pompili VJ, Imperiale MJ, Nabel GJ, et al. Gene therapy for vascular smooth muscle cell proliferation after arterial injury. Science 1994; 265: 781-784.

35. Yang Z, Simari R, Perkins N, Sang H, Gordon D, Nabel G, et al. Role of the p21cyclin-dependent kinase inhibitor in limiting intimal cell proliferation in response to arterial injury. Proc Natl Acad Sci USA 1996; 93: 7905-7910.

36. Chang MW, Barr E, Seltzer J, Jiang Y, Nabel GJ, Nabel EG, et al. Cytostatic gene therapy for vascular proliferative disorders with a constitutively active form of the retinoblastoma gene product. Science 1995; 267: 518-522.

37. Sata M, Maejima Y, Adachi F, Fukino K, Saiura A, Sugiura S, et al. A mouse model of vascular injury that induces rapid onset of medial cell apoptosis followed by reproducible neointimal hyperplasia. J Mol Cell Cardiol 2000; 32: 2097-2104.

38. Feldman LJ, Mazighi M, Scheuble A, Deux JF, De Benedetti E, Badier-Commander C, et al. Differential expression of matrix metalloproteinases after stent implantation and balloon angioplasty in the hypercholesterolemic rabbit. Circulation 2001; 103: $3117-$ 3122 .

39. Furukawa Y, Matsumori A, Ohashi N, Shioi T, Ono K, Harada A, et al. Anti-monocyte chemoattractant protein-1/monocyte chemotactic and activating factor antibody inhibits neointimal hyperplasia in injured rat carotid arteries. Circ Res 1999; 84: 306-314.

40. Hayashi S, Watanabe N, Nakazawa K, Suzuki J, Tsushima K, Tamatani T, et al. Roles of P-selectin in inflammation, neointimal formation, and vascular remodeling in balloon-injured rat carotid arteries. Circulation 2000; 102: 1710-1717.

41. Zohlnhofer D, Klein CA, Richter T, Brandl R, Murr A, Nuhrenberg $\mathrm{T}$, et al. Gene expression profiling of human stent-induced neointima by cDNA array analysis of microscopic specimens retrieved by helix cutter atherectomy: Detection of FK506-binding protein 12 upregulation. Circulation 2001; 103: 1396-1402.

42. Zohlnhofer D, Richter T, Neumann FJ, Nuhrenberg T, Wessely R, Brandl R, et al. Transcriptome analysis reveals a role of interferongamma in human neointima formation. Mol Cell 2001; 7: 10591069.

43. Saiura A, Sata M, Hirata Y, Nagai R, Makuuchi M. Circulating smooth muscle progenitor cells contribute to atherosclerosis. Nat Med 2001; 7: 382-383.

44. Sata M, Saiura A, Kunisato A, Tojo A, Okada S, Tokuhisa T, et al. Hematopoietic stem cells differentiate into vascular cells that participate in the pathogenesis of atherosclerosis. Nat Med 2002; 8: 403-409.

45. Sata M. Circulating vascular progenitor cells contribute to vascular repair, remodeling, and lesion formation. Trends Cardiovasc Med 2003; 13: 249-253.

46. Tanaka K, Sata M, Hirata Y, Nagai R. Diverse contribution of bone marrow cells to neointimal hyperplasia after mechanical vascular injuries. Circ Res 2003; 93: 783-790.

47. Friedrich G, Soriano P. Promoter traps in embryonic stem cells: A genetic screen to identify and mutate developmental genes in mice. Genes Dev 1991; 5: 1513-1523.

48. Zambrowicz BP, Imamoto A, Fiering S, Herzenberg LA, Kerr WG, Soriano P. Disruption of overlapping transcripts in the ROSA $\beta$ geo 26 gene trap strain leads to widespread expression of $\beta$-galactosidase in mouse embryos and hematopoietic cells. Proc Natl Acad Sci USA 1997; 94: 3789-3794.

49. Shimizu K, Sugiyama S, Aikawa M, Fukumoto Y, Rabkin E, Libby $\mathrm{P}$, et al. Host bone-marrow cells are a source of donor intimal smooth-muscle-like cells in murine aortic transplant arteriopathy. Nat Med 2001; 7: 738-741.

50. Hillebrands JL, Klatter FA, van Den Hurk BM, Popa ER, Nieuwenhuis $\mathrm{P}$, et al. Origin of neointimal endothelium and alphaactin-positive smooth muscle cells in transplant arteriosclerosis. $J$ Clin Invest 2001; 107: 1411 - 1422.

51. Hu Y, Davison F, Ludewig B, Erdel M, Mayr M, Url M, et al. Smooth muscle cells in transplant atherosclerotic lesions are originated from recipients, but not bone marrow progenitor cells. Circulation 2002; 106: 1834-1839.

52. Hillebrands JL, Klatter FA, Rozing J. Origin of vascular smooth muscle cells and the role of circulating stem cells in transplant arteriosclerosis. Arterioscler Thromb Vasc Biol 2003; 23: 380-387.

53. Hillebrands JL, Klatter FA, van Dijk WD, Rozing J. Bone marrow does not contribute substantially to endothelial-cell replacement in transplant arteriosclerosis. Nat Med 2002; 8: 194-195.

54. Hillebrands J, van den Hurk BM, Klatter FA, Popa ER, Nieuwenhuis P, Rozing J. Recipient origin of neointimal vascular smooth muscle cells in cardiac allografts with transplant arteriosclerosis. J Heart Lung Transplant 2000; 19: 1183-1192.
55. Grimm PC, Nickerson P, Jeffery J, Savani RC, Gough J, McKenna $\mathrm{RM}$, et al. Neointimal and tubulointerstitial infiltration by recipient mesenchymal cells in chronic renal-allograft rejection. $N$ Engl $J$ Med 2001; 345: $93-97$

56. Lagaaij EL, Cramer-Knijnenburg GF, van Kemenade FJ, van Es LA, Bruijn JA, van Krieken JH. Endothelial cell chimerism after renal transplantation and vascular rejection. Lancet 2001; 357: $33-$ 37.

57. Sata M, Sugiura S, Yoshizumi M, Ouchi Y, Hirata Y, Nagai R. Acute and chronic smooth muscle cell apoptosis after mechanical vascular injury can occur independently of the Fas-death pathway. Arterioscler Thromb Vasc Biol 2001; 21: 1733-1737.

58. Sata M, Tanaka K, Ishizaka N, Hirata Y, Nagai R. Absence of p53 leads to accelerated neointimal hyperplasia after vascular injury. Arterioscler Thromb Vasc Bio 2003; 23: 1548-1552.

59. Plump AS, Smith JD, Hayek T, Aalto-Setälä K, Walsh A, Verstuyft JG, et al. Severe hypercholesterolemia and atherosclerosis in apolipoprotein E-deficient mice created by homologous recombination in ES cells. Cell 1992; 71: $343-353$.

60. Sata M, Walsh K. Oxidized LDL activates Fas-mediated endothelial cell apoptosis. J Clin Invest 1998; 102: 1682-1689.

61. Sata M, Walsh K. Endothelial cell apoptosis induced by oxidized LDL is associated with the downregulation of the cellular caspase inhibitor FLIP. J Biol Chem 1998; 273: 33103-33106.

62. Dimmeler S, Haendeler J, Galle J, Zeiher AM. Oxidized lowdensity lipoprotein induces apoptosis of human endothelial cells by activation of CPP32-like proteases. Circulation 1997; 95: 17601763.

63. Zhang C, Cai Y, Adachi MT, Oshiro S, Aso T, Kaufman RJ, et al. Homocysteine induces programmed cell death in human vascular endothelial cells through activation of the unfolded protein response. J Biol Chem 2001; 276: 35867-35874.

64. Dimmeler S, Rippmann V, Weiland U, Haendeler J, Zeiher AM. Angiotensin II induces apoptosis of human endothelial cells: Protective effect of nitric oxide. Circ Res 1997; 81: 970-976.

65. Choi KB, Wong F, Harlan JM, Chaudhary PM, Hood L, Karsan A. Lipopolysaccharide mediates endothelial apoptosis by a FADDdependent pathway. J Biol Chem 1998; 273: 20185-20188.

66. Tricot O, Mallat Z, Heymes C, Belmin J, Leseche G, Tedgui A. Relation between endothelial cell apoptosis and blood flow direction in human atherosclerotic plaques. Circulation 2000; 101: 2450-2453.

67. McKay R. Stem cells: Hype and hope. Nature 2000; 406: $361-364$.

68. Orlic D, Kajstura J, Chimenti S, Limana F, Jakoniuk I, Quaini F, et al. Mobilized bone marrow cells repair the infarcted heart, improving function and survival. Proc Natl Acad Sci USA 2001; 98: 10344-10349.

69. Asahara T, Murohara T, Sullivan A, Silver M, van der Zee R, Li T, et al. Isolation of putative progenitor endothelial cells for angiogenesis. Science 1997; 275: 964-967.

70. Rafii S, Lyden D. Therapeutic stem and progenitor cell transplantation for organ vascularization and regeneration. Nat Med 2003; 9: $702-712$.

71. Hill JM, Zalos G, Halcox JP, Schenke WH, Waclawiw MA, Quyyumi AA, et al. Circulating endothelial progenitor cells, vascular function, and cardiovascular risk. $N$ Engl J Med 2003; 348: 593-600.

72. Korbling M, Katz RL, Khanna A, Ruifrok AC, Rondon G, Albitar $\mathrm{M}$, et al. Hepatocytes and epithelial cells of donor origin in recipients of peripheral-blood stem cells. N Engl J Med 2002; 346: $738-$ 746.

73. Yamashita J, Itoh H, Hirashima M, Ogawa M, Nishikawa S, Yurugi $\mathrm{T}$, et al. Flk1-positive cells derived from embryonic stem cells serve as vascular progenitors. Nature 2000; 408: 92-96.

74. Yurugi-Kobayashi T, Itoh H, Yamashita J, Yamahara K, Hirai H, Kobayashi T, et al. Effective contribution of transplanted vascular progenitor cells derived from embryonic stem cells to adult neovascularization in proper differentiation stage. Blood 2003; 101: 26752678.

75. Zalewski A, Shi Y, Johnson AG. Diverse origin of intimal cells: Smooth muscle cells, myofibroblasts, fibroblasts, and beyond? Circ Res 2002; 91: 652-655.

76. Moreno PR, Purushothaman KR, Fuster V, O'Connor WN. Intimomedial interface damage and adventitial inflammation is increased beneath disrupted atherosclerosis in the aorta: Implications for plaque vulnerability. Circulation 2002; 105: 2504-2511.

77. Kockx MM, Cromheeke KM, Knaapen MW, Bosmans JM, De Meyer GR, Herman AG, et al. Phagocytosis and macrophage activation associated with hemorrhagic microvessels in human atherosclerosis. Arterioscler Thromb Vasc Biol 2003; 23: 440-446. 
78. Komatsu R, Ueda M, Naruko T, Kojima A, Becker AE. Neointimal tissue response at sites of coronary stenting in humans: Macroscopic, histological, and immunohistochemical analyses. Circulation 1998; 98: 224-233.

79. Kaushal S, Amiel GE, Guleserian KJ, Shapira OM, Perry T, Sutherland FW, et al. Functional small-diameter neovessels created using endothelial progenitor cells expanded ex vivo. Nat Med 2001; 7: $1035-1040$

80. Caplice NM, Bunch TJ, Stalboerger PG, Wang S, Simper D, Miller DV, et al. Smooth muscle cells in human coronary atherosclerosis can originate from cells administered at marrow transplantation. Proc Natl Acad Sci USA 2003; 100: 4754-4759.

81. Osawa M, Hanada K, Hamada H, Nakauchi H. Long-term lymphohematopoietic reconstitution by a single CD34-low/negative hematopoietic stem cell. Science 1996; 273: 242-245.

82. Prockop DJ. Marrow stromal cells as stem cells for nonhematopoietic tissues. Science 1997; 276: 71-74.

83. Krause DS, Theise ND, Collector MI, Henegariu O, Hwang S, Gardner R, et al. Multi-organ, multi-lineage engraftment by a single bone marrow-derived stem cell. Cell 2001; 105: 369-377.

84. Alison MR, Poulsom R, Jeffery R, Dhillon AP, Quaglia A, Jacob J, et al. Hepatocytes from non-hepatic adult stem cells. Nature 2000; 406: 257.

85. Lagasse E, Connors H, Al-Dhalimy M, Reitsma M, Dohse M, Osborne L, et al. Purified hematopoietic stem cells can differentiate into hepatocytes in vivo. Nat Med 2000; 6: 1229-1234.

86. Orlic D, Kajstura J, Chimenti S, Jakoniuk I, Anderson SM, Li B, et al. Bone marrow cells regenerate infarcted myocardium. Nature 2001; 410: $701-705$.

87. Wagers AJ, Sherwood RI, Christensen JL, Weissman IL. Little evidence for developmental plasticity of adult hematopoietic stem cells. Science 2002; 297: 2256-2259.

88. Blau HM, Brazelton TR, Weimann JM. The evolving concept of a stem cell: Entity or function? Cell 2001; 105: 829-841.

89. Korbling M, Estrov Z. Adult stem cells for tissue repair: A new therapeutic concept? N Engl J Med 2003; 349: 570-582.

90. LaBarge MA, Blau HM. Biological progression from adult bone marrow to mononucleate muscle stem cell to multinucleate muscle fiber in response to injury. Cell 2002; 111: 589-601.

91. Terada N, Hamazaki T, Oka M, Hoki M, Mastalerz DM, Nakano Y, et al. Bone marrow cells adopt the phenotype of other cells by spontaneous cell fusion. Nature 2002; 416: 542-545.

92. Ying QL, Nichols J, Evans EP, Smith AG. Changing potency by spontaneous fusion. Nature 2002; 416: 545-548.

93. Wang X, Willenbring H, Akkari Y, Torimaru Y, Foster M, AlDhalimy M, et al. Cell fusion is the principal source of bonemarrow-derived hepatocytes. Nature 2003; 422: 897-901.

94. Vassilopoulos G, Wang PR, Russell DW. Transplanted bone marrow regenerates liver by cell fusion. Nature 2003; 422: $901-$ 904.

95. Campbell JH, Tachas G, Black MJ, Cockerill G, Campbell GR. Molecular biology of vascular hypertrophy. Basic Res Cardiol 1991; 86: 3-11.

96. Saiura A, Sata M, Washida M, Sugawara Y, Hirata Y, Nagai R, et al. Little evidence for cell fusion between recipient and donor- derived cells. J Surg Res 2003; 113: 222-227.

97. Miller AM, McPhaden AR, Wadsworth RM, Wainwright CL. Inhibition by leukocyte depletion of neointima formation after balloon angioplasty in a rabbit model of restenosis. Cardiovasc Res 2001; 49: 838-850.

98. Morice MC, Serruys PW, Sousa JE, Fajadet J, Ban Hayashi E, Perin $\mathrm{M}$, et al. A randomized comparison of a sirolimus-eluting stent with a standard stent for coronary revascularization. N Engl J Med 2002; 346: $1773-1780$

99. Fattori R, Piva T. Drug-eluting stents in vascular intervention. Lancet 2003; 361: 247-249.

100. Walsh K, Sata M. Is extravasation a Fas-regulated process? Mol Med Today 1999; 7: 61-67.

101. Walsh K, Sata M. Negative regulation of inflammation by Fas ligand expression on the vascular endothelium. Trends Cardiovasc Med 1999; 9: 34-41.

102. Nagata S, Golstein P. The Fas death factor. Science 1995; 267: $1449-1456$.

103. Nagata S. Apoptosis by death factor. Cell 1997; 88: 355-365.

104. Sata M, Perlman H, Muruve DA, Silver M, Ikebe M, Libermann TA, et al. Fas ligand gene transfer to the vessel wall inhibits neointima formation and overrides the adenovirus-mediated $\mathrm{T}$ cell response. Proc Natl Acad Sci USA 1998; 95: 1213-1217.

105. Sata M, Luo Z, Walsh K. Fas ligand overexpression on allograft endothelium inhibits inflammatory cell infiltration and transplantassociated intimal hyperplasia. J Immunol 2001; 66: 6964-6971.

106. Luo Z, Sata M, Nguyen T, Kaplan JM, Akita GY, Walsh K. Adenovirus-mediated delivery of Fas ligand inhibits intimal hyperplasia after balloon injury in immunologically primed animals. Circulation 1999; 99: 1776-1779.

107. Sata M, Walsh K. TNFa regulation of Fas ligand expression on the vascular endothelium modulates leukocyte extravasation. Nat Med 1998; 4: 415-420.

108. Richardson BC, Lalwani ND, Johnson KJ, Marks RM. Fas ligation triggers apoptosis in macrophages but not endothelial cells. Eur $J$ Immunol 1994; 24: 2640-2645.

109. Sata M, Suhara T, Walsh K. Vascular endothelial cells and smooth muscle cells differ in expression of Fas and Fas ligand and in sensitivity to Fas Ligand induced cell death: Implications for vascular disease and therapy. Arterioscler Thromb Vasc Biol 2000; 20: 309316.

110. Bjornson CR, Rietze RL, Reynolds BA, Magli MC, Vescovi AL. Turning brain into blood: A hematopoietic fate adopted by adult neural stem cells in vivo. Science 1999; 283: 534-537.

111. Reya T, Morrison SJ, Clarke MF, Weissman IL. Stem cells, cancer, and cancer stem cells. Nature 2001; 414: 105-111.

112. Simper D, Stalboerger PG, Panetta CJ, Wang S, Caplice NM. Smooth muscle progenitor cells in human blood. Circulation. 2002; 106: $1199-1204$

113. Simper D, Wang S, Deb A, Holmes D, McGregor C, Frantz R, et al. Endothelial progenitor cells are decreased in blood of cardiac allograft patients with vasculopathy and endothelial cells of noncardiac origin are enriched in transplant atherosclerosis. Circulation. 2003; 108: $143-149$. 